\title{
Seria a moralidade determinada pelo cérebro? Neurônios-espelhos, empatia e neuromoralidade
}

\author{
| ${ }^{1}$ Cláudia Passos-Ferreira |
}

Resumo: O objetivo do artigo é analisar o impacto do progresso das neurociências, em Recém-Doutor/ FAPERJ no particular da descoberta dos neurônios-espelhos, IMS-UERJ. Endereço eletrônico: sobre as teses referentes à moralidade. Analisamos as cmpassos@uol.com.br tentativas atuais de naturalizar a moralidade baseadas nessa descoberta, a partir da qual se reduzem os princípios éticos a propriedades biológicas $\mathrm{da}$ natureza humana. Investigamos como os estudos em psicologia sobre a função da empatia, da capacidade de se colocar na perspectiva do outro e da simulação corporificada ganharam nova credibilidade, poder explicativo e, sobretudo, relevância teórica por causa da descoberta dos sistemas de neurônios-espelhos. Como parte desse movimento, observamos novas tentativas nas pesquisas atuais em estabelecer conexôes funcionais e possivelmente causais entre o cérebro e o pensamento moral. Consideramos, numa perspectiva crítica, essas tentativas e a busca renovada pela formulação de uma ética naturalizada.

> Palavras-chave: neurônio espelho, empatia, ética, naturalismo, neuromoralidade. 


\section{A retomada do fundacionismo moral}

As pesquisas em neurociências têm alterado significativamente o papel do cérebro nas sociedades contemporâneas. $\mathrm{O}$ cérebro ganhou valor social e estatuto de identidade antropológica (EHRENBERG, 2004; VIDAL, 2005, 2009; VIDAL; ORTEGA, 2006). O cérebro social, como chama Ehrenberg (2008), vem completar a metáfora biológica do homem, na qual até mesmo os comportamentos sociais se explicam pelo funcionamento cerebral. Depois do cérebro social, chegamos ao cérebro moral, que passou a ser o substrato biológico que condiciona a moralidade humana.

Em 2005, Michael Gazzaniga publicou The Ethical Brain (2005), no qual apresenta os estudos do cérebro humano como um guia para o estudo de nossos princípios morais. O livro, de certo modo, reflete as discussões presentes em uma série de publicações e encontros científicos desse início de século, que deflagraram um debate ${ }^{1}$ entre os reducionistas vorazes, que buscam localizar no cérebro a explicação última de nossa moralidade, e os reducionistas prudentes, que advogam explicações externalistas e contextuais acerca da moralidade.

Para aqueles que achavam que o fundacionismo moral estava fora de moda, depois de Hume, Moore, Wittgenstein, Chomsky e da virada linguística do pragmatismo, assistimos nesse início do século à retomada dos estudos em psicologia moral que buscam naturalizar a ética. O que significa naturalizar a ética? A Ética Naturalizada busca mostrar que as normas morais emergem e são justificadas por processos puramente naturais e, na gramática atual, por fatos neurobiológicos. Dito de outro modo, o projeto naturalista visa a fundar a ética em categorias universais biológicas, que possam valer para todos os homens em todos os tempos.

Um dos méritos pela reabertura de um debate que parecia fadado a desaparecer foi a descoberta dos neurônios-espelhos, feita por Rizzolatti e sua equipe, em 1995 (RIZZOLATTI et al., 1996; GALLESE et al., 1996). A equipe italiana descobriu, ao pesquisar como macacos representam e reconhecem a ação motora, a existência de neurônios no córtex pré-motor do macaco que são ativados na presença de uma ação executada ou apenas observada. Verificou-se que esses neurônios respondem a um gesto particular não importando quem está executando o gesto. Se outro macaco, ou até mesmo um humano, está executando uma ação, como por exemplo, estar pegando bananas, os neurônios do córtex pré-motor do macaco que está observando a ação disparam. Esse achado empírico comprova 
que mesmo em primatas não-humanos existem mecanismos de espelhar, apreciar e compreender os alvos que estão sendo intencionados pelos seus coespecíficos.

A descoberta dos neurônios-espelhos tem modificado significativamente o modo como pensamos sobre o cérebro e nós mesmos, e tem sido considerado um dos achados mais importantes sobre a evolução do cérebro humano da última década (RAMACHANDRAN, 2000). A descoberta tem tido forte impacto nas pesquisas sobre compreensão e imitação da ação (IACOBONI et al., 1999; KOHLER et al., 2002; CARR et al., 2003; IACOBONI et al., 2005), linguagem (RIZZOLATTI; ARBIB, 1998), empatia (DECETY; JACKSON, 2004; DECETY, 2004; GALLESE et al., 2007), cognição social (GALLESE et al., 2004; OBERMAN; RAMACHANDRAN, 2007), psicopatologia (OBERMAN et al., 2005), moralidade (CASEBEER, 2003; GREENE, 2003; MOLL et al., 2003; MOLL et al., 2005; MOLL; OLIVEIRA-SOUZA, 2007) e até mesmo o campo da estética (FREEDBERG, 2007; FREEDBERG; GALLESE, 2007). E tem contribuído significativamente para reforçar ou refutar teses filosóficas e hipóteses psicológicas sobre como nos tornamos seres capazes de tomar decisões e fazer escolhas morais.

No entanto, a definição sobre o que seriam os neurônios-espelhos humanos tem-se alterado consideravelmente na última década, e até mesmo a confirmação de sua existência ou não em humanos ainda é fato controverso (MORIN, 2008). Em artigo polêmico, Dinstein e colaboradores (2008) afirmam não haver evidência sobre a existência de neurônios-espelhos em humanos, e questionam as interpretações dadas pelas pesquisas em curso sobre a função desses neurônios. Discute-se como devemos interpretar esse achado. Especula-se se a ativação da área motora quando o indivíduo observa a ação de um coespecífico significaria que o observador estaria espelhando a ação ou estaria se preparando para agir?

Em artigo publicado em 2005, Csibra (2005) questiona a interpretação dos resultados das pesquisas e especula que a função dos neurônios-espelhos talvez não seja a de "espelhar ou simular a ação observada", mas de "antecipar as possíveis respostas motoras à ação observada". Isso leva a indagar se os achados que correlacionam, por exemplo, o autismo como uma falha no sistema-espelho ou que julgam encontrar nos neurônios-espelhos a explicação para a experiência estética e moral não seriam apenas especulações apressadas de um campo ainda sob investigação. Apesar de a polêmica ainda não ter sido resolvida e não sabermos 
se os sistemas espelhos serão interpretados como antecipadores ou simuladores da ação, é inegável seu impacto nas teorias explicativas sobre a moralidade. Comprovada ou não a tese, ela já tem repercussão considerável e tem servido para caucionar determinadas teses em filosofia moral.

\section{Neurônios-espelhos}

A controvérsia científica atual acerca dos neurônios-espelhos é uma questão fascinante para qualquer sociólogo da ciência (MORIN, 2008). Os neurôniosespelhos se tornaram um objeto de estudo perfeito para quem quer entender como o projeto naturalista reducionista vem se tornando uma "ideia social" (EHRENBERG, 2008) e impregnando o imaginário social de tal forma a alterar significativamente a compreensão da subjetividade.

Os neurônios-espelhos são neurônios viso-motores que disparam tanto quando o animal realiza determinado ato como quando observa outro animal realizando o mesmo ato. Eles foram primeiro identificados no córtex pré-motor dos macacos (GALLESE et al., 1996; RIZZOLATTI et al., 1996) e depois na área de broca nos humanos (RIZZOLATTI; ARBIB, 1998). Segundo Rizzolatti e colaboradores (2001), a primeira evidência da presença de neurônios-espelhos em humanos foram os estudos eletroencefalográficos da reatividade dos ritmos cerebrais durante a observação dos movimentos, que foram realizados já na década de 50 por Gastau e Bert, confirmados recentemente por Cochin e colaboradores e Ramachandran e colaboradores (RIZZOLATTI et al., 2001). Outra fonte de suporte da evidência vem dos estudos com estimulação magnética transcranial (TMS) feito por Fadiga e colaboradores (1995), e outras técnicas (double-pulse TMS Technique usado por Strafella e Paus (2000) e H-reflex por Baldissera et al. (2001)). Por fim, outra evidência vem dos estudos com imagem cerebral que permitiram a localização das áreas envolvidas no sistema espelho dos humanos (GRĖZES et al., 1998; IACOBONI et al., 1999).

Esses estudos demonstraram uma combinação de ativação entre a observação e a execução da ação. A observação da ação estaria relacionada à ativação de áreas envolvidas no controle motor humano e indicariam que até mesmo a observação de ações intransitivas poderia produzir a ativação do córtex motor. Apesar de mostrarem que a observação da ação produzia ativação do sistema motor, essas pesquisas não permitiam a localização das áreas envolvidas. A localização das 
áreas só foi possível com o uso das tecnologias de imagem cerebral (fMRI).

Nos estudos com imagem cerebral (FOGASSI et al., 1998; GRĖZES et al., 1998; IACOBONI et al., 1999), a conclusão de que as áreas pré-motoras têm propriedades de espelho se deve ao fato de que as áreas ativadas na observação da ação são as áreas do sistema motor, e que são as mesmas áreas ativadas na execução da ação. Ou seja, a partir da identificação de padrões de excitação cortical semelhante em situações de observação, imitação e execução da ação, os pesquisadores inferiram que existe uma área que se comporta de forma a espelhar os movimentos do outro mesmo na ausência de seu próprio movimento.

Esses achados têm sido interpretados através da hipótese da combinação entre percepção e execução de açōes motoras (RIZZOLATTI et al., 2001). Segundo a hipótese, compreendemos a ação quando mapeamos a representação visual da ação observada na representação motora da mesma ação. Essa tese foi reforçada pelos achados empíricos de neurônios que são ativados mesmo na ausência da percepção visual da ação. Ou seja, mesmo sem ver a ação, macacos e humanos podem conhecer o significado da ação. Concluiu-se que podemos inferir o objetivo de uma ação mesmo quando a informação visual é incompleta ou ausente. ${ }^{2}$

O sistema espelho tem servido para ampliar o conhecimento de várias funções cerebrais. Mas o que interessa, para fins de nossa pesquisa, são as hipóteses sobre a empatia e as decisóes morais como funções que envolvem os mecanismos de espelhamento. O sistema-espelho está envolvido nas funções que dependem, em parte, do sistema motor. Se a tarefa exige compreensão da ação observada, então, as áreas motoras que codificam a ação são ativadas. Isso indica que há uma conexão intrínseca no sistema nervoso entre percepção e ação, e que a percepção seria uma simulação interna da ação (BERTHOZ, 2003).

Essas evidências vêm corroborar a hipótese - levantada por Gallese e Goldman (1998) e endossada por Gazzaniga (2005) - do cérebro como um grande "simulador da ação" (BERTHOZ; JORLAND, 2004), um gerador de hipóteses que antecipa as consequências da ação e cuja propriedade fundamental é a decisão. Segundo a Teoria da Simulação, a função essencial do cérebro humano seria simular, gerar hipóteses e tomar decisões. E seria essa capacidade neurobiológica que nos permitiria simular em nosso cérebro aquilo que se passa na mente do outro, colocando-nos no lugar da outra pessoa, partilhando suas representaçôes e compreendendo suas açôes. Daí conclui-se que essa capacidade de simular a 
perspectiva do outro estaria na base de nossa compreensão das emoções do outro, de nossos sentimentos empáticos e, consequentemente, de nossos processos de decisão moral (BERTHOZ; JORLAND, 2004).

A empatia é a capacidade de se colocar e simular a perspectiva subjetiva do outro para compreender seus sentimentos e emoções. É uma resposta afetiva deflagrada pelo estado emocional do outro e uma compreensão dos estados mentais da outra pessoa. Nos estudos empreendidos por Decety (2004), a empatia é definida como uma disposição inata baseada nos sistemas espelhos em conjugação com outras estruturas neuronais, que reúnem três capacidades: a capacidade de sentir e representar as emoções e sentimentos de si e do outro; a capacidade de adotar a perspectiva do outro e a capacidade de fazer a distinção entre o eu e o outro. A função da empatia é entendida a partir do modelo das representações partilhadas entre o eu e o outro. Segundo esse modelo, haveria um código mental comum que extrairia as intenções do outro a partir da observação de seus movimentos e expressões emocionais. A função da empatia estaria na base de sentimentos morais de compreensão do outro e sentimentos de solidariedade de ser capaz de se colocar na perspectiva do outro, e compartilhar experiências, necessidades e objetivos.

Nessa perspectiva, a Teoria da Simulação é apresentada como a teoria psicológica que melhor descreveria os mecanismos neurais subjacentes aos comportamentos morais, em detrimento dos modelos das representações hipotético-dedutivas da Teoria da Teoria, baseados na Teoria da Mente (BARON-COHEN, 1995; GOPNIK; MELTZOFF, 1997). O que os adeptos à Teoria da Simulação advogam é que nossa sensibilidade moral não é moldada por nossa capacidade cognitiva racional expressa por atitudes propositivas, de fazer inferências e metarrepresentações sobre a perspectiva do outro, como defendem os teóricos da Teoria da Mente. Nossa sensibilidade moral seria desenhada por nossa capacidade de simulação das emoções, sentimentos e intenções do outro.

Então poderíamos, grosso modo, resumir assim a equação teórica: fomos dotados pelo processo evolutivo de um cérebro com estruturas neuronais como os neurôniosespelhos que nos capacitam a simular mentalmente as ações e sentimentos do outro; essa capacidade, por sua vez, capacita-nos a reagir empaticamente em nossas interações sociais e é dessa aptidão que emergem os sentimentos morais que nos ajudam a decidir o que fazer nas situaçôes de conflito moral. 
A aceitação dessa formulação pressupõe admitir que existe uma natureza humana com qualidades e habilidades fixas e expressão inevitável em muitas situações, que vêm especificadas pela maquinaria inata do bebê. Nessa perspectiva, a empatia seria uma habilidade universal de nossa espécie, inerente a nossa estrutura, que ocuparia papel central no senso moral.

Vejamos a seguir como essas teses são usadas na fundação de uma ética naturalizada.

\section{O naturalismo na ética}

$\mathrm{Na}$ última década, assistimos à fundação de um novo campo denominado neuromoralidade (GREENE, 2003; CASEBEER, 2003; MOLL et al., 2005; MOLL; OLIVEIRA-SOUZA, 2007). A tentativa de fundar a moralidade em bases cerebrais e correlacionar comportamentos morais com achados neuroanatômicos não é recente. Desde a Frenologia de Franz Gall (1758-1828) (WILLIAMS, 1994), vemos a formação dessa equação reducionista "cérebro = mente = pensamento moral". Se a frenologia (WILLIAMS, 1994) acreditava ser capaz de identificar a mente moralmente comprometida por meio de estruturas anatômicas do cérebro, a neuromoralidade pretende identificar não apenas as estruturas neurais responsáveis pelo comportamento e sensibilidade moral mas também derivar do funcionamento cerebral o tipo de teoria moral mais compatível com nossa natureza neurobiológica.

Apesar da roupagem nova a velhas ideias, há algo que de fato parece novo nessa tentativa de refundar a moralidade em bases neurobiológicas. A novidade parece estar no uso que a Metaética tem feito das evidências empíricas em favor das teorias fundacionais da moralidade. Vale sublinhar que há uma diferença importante entre descobrir os substratos neurais subjacentes às ações morais, ou seja, identificar como o cérebro se comporta quando o indivíduo está engajado em decisões morais, e a pretensão reducionista de fundar a moral em bases neurológicas, ou seja, usar fatos neurais para justificar valores morais. Os neurônios-espelhos têm servido como comprovação robusta do caráter natural e biológico da moralidade, ou seja, como o endosso empírico que faltava às teorias que visam a naturalizar a moralidade.

Mas o que é problemático na tentativa de naturalizar a moral?

Um dos princípios da filosofia moral é que não se pode derivar o "ought" do “is”. Desde que David Hume (1711-1776) (2001) propôs essa distinção entre "o 
que devemos fazer" (enunciados prescritivos) e "como as coisas são" (enunciados descritivos), que a filosofia vem reconhecendo que os fatos que dizem respeito a como as pessoas realmente pensam ou agem não implicam fatos sobre como as pessoas deveriam agir ou pensar. As tentativas de proceder a esse tipo de derivação são chamadas de falácia naturalista.

A noção de falácia naturalista foi introduzida por George Moore (1873-1958) (1988) em sua investigação sobre o que seria o discurso ético e sua crítica ferrenha ao naturalismo ético. A falácia naturalista se aplica a todo projeto filosófico que pretenda identificar o significado de "bom" ou "certo" com qualquer outra propriedade natural ou metafísica. Portanto, é um erro identificar propriedades morais com propriedades naturais. Para Moore, é fundamental mantermos a distinção entre "que tipos de açôes devemos realizar?" e "que tipo de coisas devem existir por si mesmas?". Em seu famoso "argumento da questão aberta", Moore argumenta contra qualquer ética naturalizada e pretende provar que as "propriedades morais" não se confundem com as "propriedades naturais". O argumento de Moore tem como alvo principal o Darwinismo Social de Herbert Spencer $^{3}$ (1820-1903). E sua crítica pode ser estendida a toda a Sociobiologia que veio depois. O Projeto Sociobiológico visava a identificar o "bom" com o "mais evoluído". Se outrora era a Sociobiologia que caucionava a fundação da moral, atualmente é a "Psicologia Moral" que ocupa esse lugar. A psicologia moral é um campo de estudo que vem tentando descrever os fatos evolutivos e ontogenéticos que explicariam nosso comportamento moral.

Para evitar o perigo naturalista, a filosofia moral veio classicamente desconsiderando a psicologia moral, e é esse discurso antinaturalista que vem moldando o campo da ética moderna. A psicologia moral sempre foi vista pela filosofia como uma visão extremamente restritiva da concepção da natureza da moral. Um dos argumentos contra os estudos empíricos em psicologia moral é que os filósofos "puristas" acreditam que a autorreflexão racional poderia ela própria gerar um conjunto de afirmaçōes psicológicas sem depender da descrição contingente dos fatos sobre como as pessoas são motivadas, como certos aspectos afetivos afetam seu raciocínio moral. Os defensores da distinção entre o "deve" e o "é", entre "fato" e "valor" consideram que saber por que um indivíduo age e pensa de certo modo (p.ex. por que as pessoas foram atraídas pelos valores e instituições do nazismo) não informa nada a respeito de se esses valores e instituições são bons ou ruins. 
Nesse sentido, teoria moral não é o mesmo que psicologia moral. E como se distinguem esses campos? ${ }^{4}$

- A Psicologia Moral é a Ética Descritiva, o campo de investigação empírica dos padrões e práticas morais em todos os tempos e culturas. Como um campo descritivo, não tem força prescritiva para determinar como devemos agir.

- A Teoria Moral é a Ética Normativa, ${ }^{5}$ que tenta estabelecer princípios morais prescritivos e normativos para guiar nossa ação, nosso querer e nossa avaliação moral das açôes e pessoas.

A manutenção dessa distinção (JOHNSON, 1996) está ligada ao papel que a filosofia moral deveria ocupar em nossas vidas: o papel de guia moral que racionalmente determinaria prescrições para ação e um conjunto de regras morais que especificariam como deveríamos agir em situações concretas. Contudo, apesar dessa distinção clássica, assistimos, nos últimos anos, a retomada da ideia de que os princípios da ciência natural poderiam fornecer um fundamento para a ética normativa. Os defensores da naturalização da ética acreditam que os fatos sobre o que é certo e o que é errado estão tão disponíveis às descobertas científicas como qualquer outro fato. Atualmente, vários filósofos defendem a necessidade de incorporar uma robusta psicologia moral a toda teoria moral.

Os filósofos doutrinados nessa distinção, como Flanagan (1996), Johnson (1996), Prinz (2007), Greene (2003), mas poderíamos incluir James e Dewey nessa lista, vêm considerando essa uma visão estreita e trivial da Psicologia Moral, e têm se colocado em defesa do papel crucial da pesquisa empírica dos sistemas conceituais que subjazem o pensamento moral. Acreditam que uma psicologia moral robusta pode oferecer uma compreensão da origem, estrutura e natureza de nossos conceitos morais básicos e o modo como raciocinamos moralmente. Em resumo, eles advogam que nenhuma teoria moral deve ignorar a psicologia moral humana realista, na qual o processo de decisão e o comportamento descrito sejam plausíveis para criaturas como nós. Portanto, qualquer defesa de uma ética naturalizada significa, em última instância, a retomada da psicologia moral e a necessidade de explicar e redefinir o papel da psicologia, das ciências cognitivas ou de qualquer outra ciência da ética.

Redefinir o papel das ciências cognitivas significa lidar com o desprezo filosófico pela psicologia moral e as ciências cognitivas de modo geral. Esse desprezo filosófico, a meu ver, está baseado em dois tipos de preconceito: o 
preconceito contra o "fato empírico", como algo categoricamente diferente do "valor"; e a concepção extremamente estreita de ciência cognitiva como formalista, reducionista e não-humana. Essa visão redutiva das ciências cognitivas está diretamente relacionada à primeira geração definida pela inteligência artificial, a psicologia informacional e a teoria dos modelos formais. Essa primeira geração concebia a mente a partir da metáfora do programa computacional e tinha muito pouco a dizer sobre moralidade, política e ciências sociais. A segunda geração das ciências cognitivas reconhece o caráter corporificado, imaginativo e contextual de todo pensamento humano; e concebe a cognição humana como corporificada num organismo biológico em desenvolvimento que interage e coevolui com seu ambiente físico, social e moral.

Nesse debate podemos distinguir, como sugere Dennett (1995), três posições em relação à especificidade da reação ética, que configuram três tipos de premissas filosóficas embutidas:

- os relativistas: que Dennett chama de partidários do "gancho do céu” (skyhook), como Chomsky e Gould, que acreditam que a moralidade é apenas uma construção social; que somos constrangidos por fatores externos, representados pelo contrato social;

- os reducionistas vorazes: como H. Spencer, E. Wilson (e poderíamos incluir S. Pinker; M. Gazzaniga; A. Berthoz; W. Caseeber; J. Moll) que, ao simplificarem demais o problema, acabam por produzir respostas distorcidas e eliminar várias categorias fundamentais da nossa autoimagem. Adotam premissas eliminativistas de base e usam a ciência para justificar uma descrição reducionista de nossa moralidade;

- os reducionistas prudentes: como Dennett, Dwakins, (e incluiríamos J. Greene, J. Prinz, O. Flanagan, D. Sperber, A. Clark), que acreditam que a ética deve ser baseada em apreciações sobre a natureza humana, e preferem definir a construção da cultura e o advento da moralidade utilizando um conjunto de conceitos naturalistas-darwinistas. Ou seja, a ética não deve se opor irracionalmente à maneira como o mundo é.

Para os relativistas, não existe nenhuma lei moral que seja válida universalmente, e caso exista alguma lei moral, ela só pode ter força normativa relativa ao grupo cultural e dentro de um contexto histórico particular. Todos os padrões de avaliação moral são contingentes e específicos ao grupo. A conclusão 
relativista de que não existem leis morais universais que derivam da razão, como queriam os absolutistas morais, tem levado à defesa da moral como irracional, subjetiva e relativista. Em oposição ao relativismo, os naturalistas, sejam eles vorazes, prudentes ou pragmáticos, acreditam que as teorias morais absolutistas estão erradas, pois oferecem um relato falso do que seriam a razão e os conceitos humanos. O naturalismo consiste na proposta de encontrar aspectos fundamentais do pensamento moral na natureza humana. Mas isso não seria uma falácia naturalista? Para Dennett, por exemplo, o rótulo de falácia naturalista poderia ser aplicado ao reducionismo voraz de valores a fatos, ao invés do reducionismo prudente que pretende unificar nossas visões de mundo, ao ponto que nossos valores éticos não se oponham irracionalmente ao modo como o mundo é.

Para os naturalistas prudentes, como Flanagan (1996), a ética naturalizada não é uma ética psicologizada, mas é a ideia de que a ética possui dois componentes: - o componente descritivo-genealógico-nomológico: que especifica capacidades e propensões básicas da natureza humana e explica como as pessoas sentem, pensam e agem em relação às questôes morais;

- o componente normativo, que explica por que certas normas e valores são melhores que outros e busca sistematizar os modos de sentir, viver e ser a que nós, como criaturas morais, deveríamos aspirar.

$\mathrm{Na}$ última década, vários filósofos vêm defendendo uma concepção de ética naturalizada que oferece um papel para a psicologia moral e as neurociências. Naturalizar a ética significa derivar a moral normativa da moral descritiva. E, para as neurociências, os fatos descritivos dos quais derivariam a natureza moral são os mecanismos neurais subjacentes à cognição moral. E são esses mecanismos que as neurociências se propõem a descrever. Apesar de reconhecerem que há uma gama ampla de processos cognitivos e neurais implicados nas decisões morais, os naturalistas buscam isolar quais seriam os constituintes neurais que quando não ativados (por lesão ou deficiência, p.ex.) não deflagrariam certas respostas morais. E avaliam quais teorias morais seriam as mais neurofisiologicamente plausíveis. Vejamos, a seguir, como esses mecanismos são explicados no caso da empatia.

\section{Empatia e tomada de decisão moral}

Como vimos, a hipótese de que as emoções e os sentimentos empáticos estariam na base de nossas decisões morais, hipótese defendida pela vertente humeana 
em filosofia moral contrária ao racionalismo moral kantiano (RORTY, 1994, PASSOS-FERREIRA, 1998), tem ganho significativo relevo com a descoberta das bases neurais envolvidas nessas funções. Uma série de estudos empíricos com imagem cerebral está sendo desenvolvida para explorar a correlação entre sentimentos empáticos e pensamento moral, a partir dos mecanismos neurais subjacentes a ambos processos. As pesquisas de Casebeer (2003), Greene (2003) e Moll $(2003,2005,2007)$ sugerem que existe uma base neural para o pensamento moral. A partir da hipótese de que a função essencial do cérebro é tomar decisões, esses autores acreditam que existe um tipo de compasso universal no cérebro humano que seria ativado durante o processo de raciocínio moral.

A dificuldade de desenhar um experimento em psicologia moral com uso de imagem cerebral que examine nosso pensamento moral está diretamente relacionada à variedade de teorias morais. Casebeer criou um protocolo experimental que tem sido reproduzido em diferentes desenhos de pesquisas. O paradigma experimental coloca os sujeitos do experimento diante de dilemas morais e observam as reações cerebrais nos diferentes tipos de julgamento moral. A seguir, verifica-se como o cérebro se comporta em relação a três teorias morais: o utilitarismo, a deontologia e a teoria da virtude. Casebeer (2003) define de modo simplificado essas teorias em três máximas:

- A atitude utilitarista é expressa pela crença de que as boas ações morais são aquelas que levam mais felicidade a um maior número de pessoas.

- A atitude kantiana não se preocupa com o resultado final da ação, mas com a intenção que a produziu, pois acredita que é mais importante respeitar os direitos de uma pessoa do que atingir um resultado ideal.

- A atitude virtuosa é aquela que busca cultivar as virtudes e evitar os vícios. Para Casebeer, essas diferentes teorias morais sublinham regiōes cerebrais distintas. A Deontologia Kantiana estaria relacionada com a região frontal; o Utilitarismo de Mill se expressaria nas regiões pré-frontais, límbicas e sensoriais; e a Teoria da Virtude estaria relacionada com a coordenação apropriada da ação.

O dispositivo experimental é o seguinte: o experimentador coloca diferentes sujeitos em aparelhos de imagem cerebral (scanners) e verifica quais regiōes de seu cérebro são ativadas quando ele está diante de certos dilemas morais. A depender da área cerebral ativada, indica-se que região neural foi usada no processo de decisão moral. 
Os resultados sugerem que quando o indivíduo está querendo agir baseado numa crença moral é porque a parte emocional do cérebro se tornou ativa quando se considerou a questão moral. Quando outro problema moralmente equivalente é apresentado e o indivíduo decide não agir moralmente, é porque a parte emocional do cérebro não se tornou ativa. Os achados indicam que as regiôes do cérebro normalmente ativadas em processos emocionais são ativadas no julgamento moral, mas não são ativadas em julgamentos que não incluem nossas crenças morais. Conclui-se que quando decidimos agir de acordo com uma crença moral, é porque a parte emocional de nosso cérebro se tornou ativa. E quando não agimos moralmente, essa parte do cérebro não é ativada. Isso mostraria como a resposta automática cerebral poderia predizer que tipo de resposta moral vai ser dada.

Contudo, como esclarece Greene (2003), muitos dos argumentos em favor da continuidade entre ética e ciência natural têm sido insuficientes na tentativa de oferecer suporte científico às teorias morais. Por exemplo (e aqui o argumento é meu), mesmo que esteja correta a hipótese de que nosso cérebro reage empaticamente a situações morais, simulando emocionalmente o comportamento do outro, essa capacidade de espelhamento e simulação das emoções pode até descrever os mecanismos necessários para o sentimento moral. Porém, a simples presença desse mecanismo não garante o sentimento moral.

Um sociopata, por exemplo, é capaz de imitar um comportamento moral e ter comportamentos similares ao que consideramos um comportamento moral correto, e, por vezes, usa eficazmente essa sua capacidade de imitação para atrair as vítimas de seus atos cruéis. Isso sugere que a capacidade de simular os comportamentos morais não é suficiente para garantir o senso de moralidade. Ao contrário, a capacidade de espelhamento pode ser usada, em certos contextos, para aumentar a eficácia do gesto cruel. A entrada na moralidade parece necessitar da introjeção de interdições, normas e sentimentos empáticos que estão além de nossa capacidade de simulação do gesto, sensação e emoção do outro. Podemos conceder aos neurônios-espelhos o estatuto de mecanismo necessário e até hipotetizar que um defeito, falha ou ausência desse mecanismo pode produzir ausência de empatia e, consequentemente, de sentimento moral como no caso das pessoas portadoras de autismo. Mas sua presença não parece ser condição suficiente para garantir o desenvolvimento da moralidade. 
A hipótese de que, pelas evidências do sistema espelho, nosso cérebro funciona como um simulador da mente e que isso explicaria como estabelecemos as interações sociais, deixa de fora um elemento fundamental, inerente a toda relação social, que é o valor. A noção de valor é sempre particular a uma forma de vida. Ainda não se sabe exatamente que tipo de interação é responsável pelo desenvolvimento dos sentimentos morais, mas com certeza implica uma estrutura que ultrapasse a díade eu-outro da simulação. Nosso pensamento moral, a meu ver, emerge sempre de uma relação intersubjetiva triádica de eu-outro-valor (PASSOS-FERREIRA, 2006; ROCHAT; PASSOS-FERREIRA, 2008).

Um dos autores que defendem certo tipo de triadismo é Johnson. Para Johnson (1996), a imaginação tem papel fundamental em nosso pensamento moral. Somos criaturas imaginativas, desde nossos atos automáticos de percepção até nossa mais abstrata conceitualização e pensamento. Nosso raciocínio moral depende em grande parte de nossa imaginação, das imagens, metáforas, narrativas. O raciocínio moral usa conceitos estruturados de modo imaginativo e requer a imaginação para discernir o que é moralmente relevante nas situaçōes e para compreender empaticamente como outros vivenciam as coisas. Os princípios morais sem a imaginação moral tornam-se triviais, impossíveis de serem aplicáveis. Nossos conceitos morais mais fundamentais são definidos metaforicamente, com múltiplos mapas metafóricos para um único conceito. $\mathrm{O}$ modo de conceitualizarmos uma situação particular depende de nosso uso de metáforas conceituais sistemáticas que compõem o entendimento comum dos membros de nossa cultura.

A pretensão do autor é menos oferecer um guia moral de "qual é a coisa certa a fazer" e muito mais oferecer uma visão de como nos tornamos moralmente sensíveis. Johnson não descarta os avanços das neurociências como importantes para ampliar nosso conhecimento sobre o pensamento moral. Concorda que as ciências cognitivas e as neurociências têm importantes resultados que nos ajudam a redefinir nossas convicções morais. A diferença está no estatuto dado aos achados empíricos e no modo como são incluídos na defesa de seus argumentos.

\section{Conclusão}

À guisa de conclusão, aqui me filio àqueles que defendem a incorporação prudente da psicologia moral à teoria moral. Mas por que precisamos incorporar uma robusta psicologia moral à teoria moral? Ao responder à pergunta, Johnson (1996) dá motivos satisfatórios em defesa da psicologia moral: 
nossa moralidade é uma moralidade humana, e deve ser uma moralidade dirigida a preocupações humanas, realizável por criaturas humanas como nós, e aplicáveis aos tipos de situações problemáticas que encontramos em nossas vidas. Isso quer dizer que não podemos fazer boa teoria moral sem saber muito sobre motivação humana, a natureza do self, a natureza dos conceitos humanos, como nossa razão funciona, como somos socialmente construídos, e uma penca de outros fatos sobre quem nós somos e como nossa mente opera (JOHNSON, 1996, p. 49).

O que Johnson propõe é a superação da dicotomia. Contudo, a posição que mais nos comove é a compatibilização dos dois campos, pois assim parece que garantimos a preservação de nosso esquema conceitual, para usar a expressão de Davidson (1984), em que boa parte de nossos valores e conceitos normativos estão expressos. Por um lado, sem sabermos como nossa mente opera e como desenhamos nossos problemas morais, estaremos condenados a uma psicologia moral tirânica, absoluta ou estúpida. Por outro, se aderirmos completamente à psicologia moral e abandonarmos a distinção entre dever e ser, o que nos resta é uma moralidade restrita, primitiva, como mostra Prinz (2007) em seu argumento contra a natureza (Against Nature). Sabemos que não há nenhuma conexão a priori entre o conhecimento de nossos conceitos morais e as regras morais específicas, e é por isso que a psicologia moral nunca vai poder oferecer um conjunto exaustivo de nossas prescrições para a vida moral. Como afirma Prinz (2007):

Se pudéssemos de algum modo eliminar todas as influências da cultura e retornar aos nossos valores pré-morais, que valores teríamos em nosso estado natural? Para fazer isso, teríamos que eliminar o casamento e a propriedade, teríamos que abandonar preocupaçôes com a justiça global, teríamos que tolerar o castigo corporal, e talvez algum canibalismo e estupro [...] provavelmente seríamos muito parecidos com os chimpanzés.

Talvez, pudéssemos sustentar essa existência chimpanzé por um tempo. Talvez as primeiras populações de humanos foram assim. Mas não por muito tempo. Nossos ancestrais tiveram moradias, roupas e ferramentas. Travaram batalhas uns com os outros, organizaram caçadas, expedições, e inventaram organizações políticas para os seus clãs. Uma vez que essas coisas estão postas, os valores naturais não podem mais servir como simples guia para a ação. [...]

Mas estamos num posição desvantajosa por causa disso? Deveríamos nos empenhar para retornarmos à Savana Mítica? A resposta é óbvia. Por um lado, não podemos retornar ao estado puro e desinformado pelo conhecimento e tecnologias que acumulamos em milênios de evolução cultural. Por outro, não existe nenhum modo de justificar a afirmação de que nosso estado natural é melhor simplesmente em virtude de ser mais natural. Nosso estado natural encoraja a construção de instituições e valores sociais. Nossos valores são agora, e serão sempre, produtos tanto da natureza quanto do desenvolvimento. A Ética Evolucionária, esse nome inapropriado, oferece uma visão 

quais a moralidade se desenvolve, mas uma investigação dessas fronteiras é incompleta e totalmente desprovida de implicaçôes normativas (PRINZ, 2007, p. 286-287).

Portanto, uma defesa à incorporação da psicologia moral não significa uma adesão cega à Ética Evolucionária que fundamenta nosso pensamento moral em genes da moralidade, como expressão de um instinto moral como um legado da evolução (SPINKER, 2008). Mas sim um melhor entendimento das fronteiras biológicas nas quais evoluem os mecanismos neurais e cognitivos subjacentes ao pensamento moral. Pois, apesar de nossa estrutura biológica de pensamento erguer fronteiras e limites ao exercício de nossa moralidade, ela é incapaz de explicar a metaforização de nossos conceitos morais e a emergência de valores sociais como guia para nossas ações morais.

\section{Referências}

BALDISSERA, F. et al. Modulation of spinal excitability during observation of hand actions in humans. European Journal of Neuroscience, v. 13, n. 1, p. 190-194, 2001.

BARON-COHEN, S. Mindblindness: an essay on autism and theory of mind. Cambridge, Mass.: MIT Press, 1995.

BERTHOZ, A. La Décision. Paris: Odile Jacob, 2003.

BERTHOZ, A.; JORLAND, G. (Org.). L'Empathie. Paris: Odile Jacob, 2004.

CARR, L. et al. Neural mechanisms of empathy in humans: a relay from neural systems for imitation to limbic areas. PNAS, v. 100, n. 9, p. 5497-5502, 2003.

CASEBEER, W. Moral cognition and its neural constituents. Nature Reviews Neuroscience, v. 4, n. 10, p. 841-847, 2003.

CSIBRA, G. Mirror neurons and action observation. Is simulation involved? What do mirror neurons mean? 2005. Disponível em <http://www.interdisciplines.org/mirror/papers/4 >. Acesso em: 03 jan 2005.

DAVIDSON, D. On very Idea of conceptual scheme, in Inquiries into truth \& interpretation. New York: Oxford University Press, 1991, p. 183-198.

DECETY, J. L'empathie est-elle une simulation mentale de la subjectivité d'autrui? In: BERTHOZ, A.; JORLAND, G. (Org.). L'Empathie. Paris: Odile Jacob, 2004, p. 53-88.

DECETY, J.; JACKSON, P. The functional architecture of human empathy, Behavioral and Cognitive Neuroscience Reviews, v. 3, n. 2, p. 71-100, 2004.

DENNETT, D. Darwin's dangerous Idea: evolution and the meanings of life. New York Simom \& Schuster, 1995. 
DINSTEIN, I. et al. Executed and observed movements have different distributed representations in human aIPS. Journal of Neuroscience, v. 28, n. 44, p. 11231-11239, 2008. EHRENBERG, A. Le sujet cérebral. Esprit, v. 11, p. 130-155, 2004.

. Le cerveau "social". Chimère épistémologique et vérité sociologique, Esprit, v. 1, p. 79-103, 2008.

FADIGA, L. et al. Motor facilitation during action observation: a magnetic stimulation study. Journal Neurophysiology, n. 73, p. 2608-2611, 1995.

FLANAGAN, O. Ethics naturalized: ethics as human ecology. In: MAY, L.; FRIEDMAN, M.; CLARK, A. (Org.) Mind and morals: essays on cognitive science and ethics. Cambridge, Mass.: MIT Press, 1996, p. 19-43.

FOGASSI, L. et al. Neurons responding to the sight of goal directed hand/arm actions in the parietal area PF (7b) of macaque monkey. Society Neuroscience Abstract, v. 24, p. 257, 1998.

FREEDBERG, D. Empathy, Motion and Emotion. In HERDING, K.; KRAUSE WAHL, A. (Ed.). Wie sich Gefuhle Ausdruck verschaffen: Emotionen in Nahsicht. Berlin: Driesen, 2007, p. 17-51.

FREEDBERG, D.; GALLESE, V. Motion, emotion and empathy in esthetic experience. Trends in Cognitive Sciences, v. 11, n. 5, p. 197-203, 2007.

GAZZANIGA, M. The ethical brain. the science of our moral dilemmas. New York: Harper Perennial, 2005.

GALLESE, V. et al. Action recognition in premotor cortex, Brain, v. 119, n. 2, p. 593-609, 1996.

GALLESE, V.; KEYSERS, C.; RIZZOLATTI, G. A unifying view of the basis of social cognition. Trends in cognitive sciences, v. 8, n. 9, p. 396-403, 2004.

GALLESE, V.; EAGLE, M.; MIGONE, P. Intentional attunement: mirror neurons and the neural underpinnings of the interpersonal relations. J. American Psychoanalytic Association, v. 55, n. 1, p. 131-175, 2007.

GALlESE, V.; GOLDMAN, A. Mirror neurons and the simulation theory of mindreading. Trends in Cognitive Sciences, v. 2, n. 12, p. 493-501, 1998.

GOPNIK, A.; MELTZOFF, A.N. Words, thoughts and theories. Cambridge, Mass.: MIT Press, 1997.

GREENE, J. From neural 'is' to moral 'ought': what are the moral implications of neuroscientific moral psychology? Nature Reviews Neuroscience, v. 4, n. 10, p. 847-850, 2003.

GREZES, J.; COSTES, N.; DECETY, J., Top-down effect of strategy on the perception of human biological motion: a PET investigation. Cognitive Neuropsychology, v. 15, n. 6-8, p. 553-582, 1998.

HUME, D. Tratado da natureza humana. São Paulo: UNESP, 2001.

IACOBONI, M. et al. Cortical mechanisms of human imitation. Science, v. 286 n. 5449, p. 2526-8, 1999. 
IACOBONI, M. et al. Grasping the intentions of others with one's owns mirror neuron system. PLoS Biology, v. 3, n. 3, p. 529-535, 2005.

JOHNSON, M. How moral psychology changes moral theory. In MAY, L.; FRIEDMAN, M.; CLARK, A., Mind and morals. Cambridge, Mass.: MIT Press, 1996, p. 45-67.

KOHLER, E., et al. Hearing sounds, understanding, actions: action representation in mirror neurons. Science, v. 297, n. 5582, p. 846-848, 2002.

MACINTYRE, A. Historia de la ética. Buenos Aires: Paidós Ibérica, 1991.

MOLL, J.; OLIVEIRA-SOUZA, R.; ESLINGER, PJ. Morals and the human brain: a working model. NeuroReport, v. 14, n. 3, p. 299-305, 2003.

MOLL, J., et al. The neural basis of human moral cognition. Nature Reviews Neuroscience, v. 6, n. 10, p. 799-809, 2005.

MOLL, J.; OLIVEIRA-SOUZA, R. Moral judgments, emotions and the utilitarian brain. Trends in Cognitive Sciences, v. 11, n. 8, p. 319-321, 2007.

MOORE, G. Principia Ethica. New York: Prometheus Books, 1988.

MORIN, O. No evidence of human mirror neurons. International Cognition and Culture Institute, 2008. Disponível em: <http://www.cognitionandculture.net/index. php? option $=$ com_content $\&$ view $=$ article $\&$ id $=223:$ do - we-have- mirror-neurons - at all\&catid=32:oliviers-blog \&Itemid=34> Acesso em: 18 nov. 2008.

OBERMAN, L.; RAMACHANDRAN, V. The simulating social mind: the role of the mirror neuron system and simulation in the social and communicative deficits of autism spectrum disorders, Psychological Bulletin, v. 133, n. 2, p. 310-327, 2007.

OBERMAN, L.. et al. EEG evidence for mirror neuron dysfunction in autism spectrum disorders. Cognitive Brain Research, v. 24, n. 2, p. 190-198, 2005.

PASSOS-FERREIRA, C. Sobre a trajetória da reflexão ética e as implicações do neopragmatismo na clínica terapêutica. Saúde, Sexo e Educação, v. 1, n. 15, p. 14-23, 1998.

. Origens da Interioridade: autoconhecimento e externalismo. 2006. Tese (Doutorado em Saúde Coletiva) - Instituto de Medicina Social, Universidade do Estado do Rio de Janeiro, Rio de Janeiro, 2006.

PINKER, S. The moral instinct, New York Times. Sunday Magazine, Jan. 13, 2008.

PRINZ, J. The emotional construction of morals, Oxford: Oxford University Press, 2007.

RAMACHANDRAN, V.S. Mirror neurons and imitation learning as the driving force behind "the great leap forward" in human evolution. Edge, 2000. Disponível em: <http://www.edge. org/3rd_culture/ramachandran/ramachandran_p1.htm>. Acesso em: 18 nov 2008.

RIZZOLATTI, G., et al. Premotor cortex and the recognition of motor actions. Cognitive Brain Research, v. 3, n. 2, p. 131-141, 1996. 
RIZZOLATTI, G.; ARBIB, M.A. Language within our grasp. Trends in Neuroscience, v. 21, n. 5, p. 188-194, 1998.

RIZZOLATTI, G.; FOGASSI, L.; GALLESE, V. Neurophysiological mechanisms underlying the understanding and imitation of action. Nature Reviews Neuroscience, v. 2, n. 9, p. 661-669, 2001.

ROCHAT, P.; PASSOS-FERREIRA, C. From Imitation to reciprocation and mutual recognition. In: PINEDA, J. (Ed.) Mirror neurons systems. The role of mirroring processes in social cognition. New York: Humana Press, 2008. p. 191-212.

RORTY, R. Droits de l'homme, rationalité et sentimentalité. In: Ambigûitéet limites du postmodernisme. Paris: Libraire Philosophique J. Vrin, 1994, p. 13-36.

STRAFELLA, A.P.; PAUS, T. Modulation of cortical excitability during action observation: a transcranial magnetic stimulation study. NeuroReport, v. 11, n. 10, p. 2289-2292, 2000.

VIDAL, F. Le sujet cérébral: une esquisse historique et conceptuelle. Psychiatrie, sciences humaines, neuro-sciences, v. 3, n. 11, p. 37-48, 2005.

. Brainhood, anthropological figure of modernity. History of The Human Sciences, v. 22, n. 1, p. 5-36, 2009.

VIDAL, F.; ORTEGA, F. O sujeito cerebral. Novo paradigma defende abordagem multidisciplinar para compreender a experiência humana. Scientific American Brasil, v. 52, p. 20-20, 2006.

WILLIAMS, E.A. The physical and moral. Anthropology, physiology, and philosophical medicine in France, 1750-1850. Cambridge: Cambridge University Press, 1994.

\section{Notas}

${ }^{1}$ Ver as conferências "What do mirror neurons mean?" (CSIBRA, 2005) e os artigos publicados na Nature Neuroscience (2003) sobre as bases neurais da moralidade.

${ }^{2}$ Isso não significa dizer que o macaco entende a intenção da ação (só porque a ação observada é realizada), mas ele é capaz de entender o que o agente está fazendo. Daí conclui-se que a percepção e a execução da ação partilham um mesmo substrato biológico.

${ }^{3}$ H. Spencer, pai do Darwinismo Social, almejava fundar a filosofia moral e política em princípios evolucionários. Sobre a análise que Moore faz da posição de Spencer, ver MacIntyre (1991).

${ }^{4} \mathrm{O}$ campo da Ética se divide em três domínios: 1) Ética Descritiva que faz a investigação empírica dos padrões e práticas morais; 2) Ética Normativa, que estabelece princípios morais prescritivos e normativos para guiar a ação; 3) Metaética, que faz a análise conceitual do status cognitivo e do conteúdo semântico dos conceitos morais, buscando clarificar conceitos morais fundamentais, tais como bem, certo, obrigação e regra.

${ }^{5}$ Os estudos em metaética representaram grande parte dos estudos em filosofia moral do século passado. Foi com a ética normativa e não-fundamentalista de John Rawls que os filósofos voltaram a se sentir livres para fazer ética normativa (JOHNSON, 1996). 


\section{Does the brain have anything to do with morality? Mirror neurons, empathy and neuromorality}

This paper aims to consider the impact of progress in the neurosciences, in particular the discovery of mirror neurons, on the study of morality. It analyzes the current attempts at naturalizing moral principles based on this discovery, reducing human morality to basic biological properties. It explores how psychological studies on empathy, perspective taking and embodied simulation have gained new credibility, explanatory power, and overall theoretical "traction" because of the discovery of mirror neuron systems. As part of this movement, there are now renewed attempts by researchers at establishing functional links, possibly causal links, between brain and moral thought. These attempts and the renewed quest toward naturalizing ethics are critically considered.

Key words: mirror neurons, empathy, ethics, naturalism, neuromorality. 